Fecha de recepción: abril 2019

Fecha de aceptación: octubre 2019

Versión final: mayo 2020

\section{Posibilidades de la imagen en tiempos de oscuridad}

Alejandra Niedermaier *

Resumen: Si el cuaderno manifiesta, en su totalidad, una continuidad con el anterior, realizado también entre las Universidades de Palermo y Nacional de Colombia, este artículo intenta ser una expansión de lo expresado en el ensayo "Cuando me asalta el miedo, creo una imagen" allí albergado. La contemporaneidad y su creciente giro visual solicitan profundizar sobre sus distintos aspectos. Se concibe a la imagen como una condición de posibilidad de otorgar una pensatividad (en tanto distribución de lo sensible y lo inteligible) a los distintos aspectos que pone en evidencia, ya sea cotidianeidades, pequeños relatos, comunidades, identidades, aspectos geopolíticos y otros. Por ello, el presente escrito está dividido en dos apartados: "Derroteros" en el que se dará cuenta de las distintas manifestaciones de la visualidad, a través de su incidencia simbólica y capacidad de crear imaginarios, su manifestación como síntoma de diferentes problemáticas, la acción del gesto del productor y finalmente, su aptitud para la generación de relatos.

Bajo el apartado "La imagen como área de trabajo" se analizará la presente problemática de uso para finalizar con algunas consideraciones sobre el relato didáctico que resulta menester a partir de las examinaciones realizadas.

Palabras clave: visualidad - pensatividad - sensible - inteligible - didáctica.

[Resúmenes en inglés y portugués en las páginas 170-171]

$\left.{ }^{\star}\right)$ Fotógrafa, docente e investigadora. Magister en Lenguajes Artísticos Combinados (UNA). Profesora de la Universidad de Palermo en el Área de Investigación y Producción de la Facultad de Diseño y Comunicación. Coordinadora Académica de la Escuela de Fotografía Motivarte, docente del Posgrado de Lenguajes Artísticos Combinados de la UNA. Publica libros y ensayos acerca de los derroteros del lenguaje visual desde sus aspectos históricos y contemporáneos como así también sobre los aspectos didácticos. Forma parte del Cuerpo Académico de la Maestría en Gestión del Diseño. Miembro del Consejo Asesor Académico. Dirige el Proyecto de Investigación Giros y perspectivas visuales. Pertenece a la Facultad de Diseño y Comunicación desde el año 2008. 


\title{
Derroteros
}

\author{
"No una imagen justa, sino justamente una imagen"
} Jean Luc Godard (2011, p. 41)

\section{La formación del imaginario}

Una ultra apretada síntesis de la importancia de la imagen conduce primeramente a la prehistoria con las pinturas rupestres y las diferentes tallas, incluyendo las precolombinas. André Leroi-Gourhan contemplaba la mano y la cara fósiles como herramientas para el gesto y la palabra dando cuenta así de los primeros dispositivos de comunicación. Las producciones resultan pues un punto de encuentro entre representación y simbolización. Por su parte, a partir del cristianismo la imagen se convierte en un elemento trasmisor de su épica pudiendo mencionarse El manto de Santa Verónica como representación icónica y otras como elemento didáctico evangelizador.

Dando cuenta de que la imagen contiene una valor de signo semiótico y que pertenece también al orden del pathos, se encuentra el mito de origen de la pintura, el cuadro $L a$ doncella de Corinto plasmado por diversos artistas, entre ellos, Joseph Wright of Derby entre 1783 y 1784 . El mismo está basado en la historia de Plinio que relata sobre el anhelo de una doncella que, ante la partida de su enamorado, comienza a bosquejar su perfil para conservar su imagen. Jean Jacques Rousseau invoca esta escena diciendo: "el amor, se dice, fue el inventor del dibujo. (...) Los primeros motivos del hombre para hablar fueron las pasiones" (en Niedermaier, 2008, p. 23).

La trasmisión del derrumbe de las torres gemelas el 11 de septiembre de 2001 marca un nuevo hito en la historia de la imagen y su posibilidad de espectacularización. Justamente, Guy Debord diagnosticaba: "Allí donde la realidad se transforma en simples imágenes, las simples imágenes se transforman en realidad" (en Fontcuberta, 2016, p. 7).

Sucesos como el asesinato a John Lennon en 1980 y la tragedia de Charlie Hebdo en París en 2016, ratifican su pertenencia al orden del pathos. Mark Chapman, el asesino de Lennon, declaró en 1992 que no era consciente de estar disparándole a una persona real, sino a la imagen que aparecía en la portada de un disco.

Pero también se puede distinguir la condición de posibilidad de la imagen de producir modificaciones sobre el devenir de la humanidad a través de la instantánea que circulara en 2017 (varias veces reproducida de distintas maneras) del niño sirio ahogado en las costas de Turquía dando cuenta de la problemática contemporánea de los refugiados.

A partir de los espejos de obsidiana, llamados tezcatl, de la cultura mezoamericana que, desde profundidades humosas, permitían visualizar otros tiempos y lugares y reflejaban al observador y al objeto al mismo tiempo, se continuará con algunas consideraciones teóricas con el objeto de comprender mejor la incidencia de la imagen sobre la subjetividad, sobre el imaginario individual y colectivo y sobre sus posibilidades simbólicas.

En Por el camino de Swann, primer tomo de En busca del tiempo perdido de Marcel Proust, la evocación infantil epifánica del protagonista, al tomar un té acompañado por una magdalena, se ha convertido en un mito. El recuerdo de su infancia y de sus veranos en Combray regresa a través de los pedacitos de la magdalena, humedecidos en té, que él come. 
Este episodio contiene, en su totalidad, la teoría proustiana sobre el espacio, el tiempo y la memoria ya que la voluntad del autor era abarcar la realidad en todas sus dimensiones, adentrándose en distinguir la memoria voluntaria de la involuntaria. De ahí que Proust, interesado justamente por el mencionado carácter evocador del dispositivo fotográfico, al ver las imágenes de su abuela opinaba: "El gran hecho que debemos reconocer no es que las fotografías (...) tratan de hacernos creer que ella todavía está aquí, sino que sucede lo contrario, lo que debemos recordar es que ella ya no vive" (Brassai, 2001).

El arte es, de esta forma, para Proust "el medio de liberar esa parte incomunicable de nosotros mismos" (ibid).

Según Walter Benjamin la eternidad que Proust deja entrever convoca a pensar la relación de las variables cronotópicas ya que se trata "no de un tiempo sin límites sino de un tiempo cruzado por el espacio" (en Cadava 2014, p. 142).

A su vez, Roland Barthes acuerda con Proust, al plantear que a través de la fotografía se activa una simultánea y extraña percepción del aquí y del allá, del entonces y del ahora que conlleva a una melancolía caracterizada en sus textos como "esto ha sido" (1982).

En el mismo sentido, Benjamin aportaba: “(...) imagen es aquello en lo cual lo que ha sido se une como en un relámpago con el ahora en una constelación. En otras palabras: la imagen es la dialéctica en suspenso" (en Agamben, 2009, p. 100).

El mismo autor en su texto La obra de arte en la era de su reproductibilidad técnica registraba las imágenes de Eugene Atget como el inicio en el cual "las placas fotográficas comienzan a convertirse en pruebas del proceso histórico". En Pequeña historia de la fotografía señalaba que sólo a través de este lenguaje podemos percibir el "inconsciente óptico" del mismo modo que gracias al psicoanálisis estamos en condiciones de percibir el "inconsciente pulsional" (Benjamin, 2007, p. 160 y 187). De alguna manera el inconsciente no deja de funcionar en la historia ya que la agita tal como la fotografía realiza con la memoria. Al respecto Henri Bergson afirmaba que la formación del recuerdo se estructura a partir de una percepción que le es contemporánea. Incluso al trabajar sobre el dejà $v u$ mencionaba que el recuerdo no sigue a la percepción y lo define como un "recuerdo del presente". Deleuze al comentar a Bergson escribió: "el pasado es 'contemporáneo' del presente que 'fue" (1987, p. 54) La toma fotográfica entonces recorta el presente para ingresarlo a su imagen. En este sentido la fotografía trabaja la profundidad del tiempo (en la misma acepción que la profundidad de campo).

Por lo expresado hasta aquí se puede comprender que la imagen incide directamente sobre lo imaginario y lo real a través de lo simbólico. Julio César Goyez Narvaez considera al respecto que "El aspecto simbólico de las artes audiovisuales es capaz de articular como experiencia el desgarro que el sujeto padece en su combate con lo real" (2015, p. 86). Así lo Real, el concepto de verdad y la realidad resultan elementos constitutivos de la inteligibilidad y la subjetividad en virtud de que lo Real no se encuentra solamente en el exterior de un sujeto sino que habita también en su interior y muta constantemente. A su vez el imaginario se conforma por un conjunto de producciones (visuales y lingüísticas) que actúan como un compuesto coherente y dinámico que alberga una función simbólica. Es a través del imaginario que se tejen las relaciones con el mundo y con el sentido. Cada grupo social conforma su propio sistema de modelización de subjetividad, una cierta cartografía en la que intervienen referencias míticas, rituales y simbólicas. Por ello el lenguaje visual 
vehiculiza la constitución de un imaginario individual y social. La imagen se ocupa pues de las tensiones y tracciones que existen entre lo imaginario y lo real e instaura relaciones inéditas. Coadyuva con la construcción de un espacio abierto y en permanente disputa. Los procesos de "desplazamiento" y "condensación" que Sigmund Freud desarrolló para la actividad onírica resultan relevantes para el campo visual en tanto la formación del imaginario citado. El concepto de desplazamiento informa sobre el traslado en imágenes de las preocupaciones esenciales del hombre, tanto individuales como colectivas. En cuanto a la condensación, toda imagen contiene una importante concentración de significaciones. François Soulages apunta que en el sueño y en la producción visual se elude la frontera entre lo consciente, lo inconsciente y la censura a la que se refería Freud (2016, p. 13). Así los textos visuales juegan con el sentido de su materia, sentido como sensualidad (en términos de su palpable vivacidad y seducción) y sentido como significación.

La fotografía ha sufrido una serie de desplazamientos, deslizamientos. Uno de ellos es la trasmutación del concepto de huella. Más allá del concepto peirciano del término y que se aplicaba muy bien a la fotografía analógica, con el advenimiento de la imagen numérica se puede entrever otro concepto de huella, de traza. Desde la tradición del pensamiento fotográfico que no conoció el paradigma digital -como es el caso de Walter Benjaminhasta analistas contemporáneos que comprenden ambos -por nombrar algunos: Rosalind Krauss, Georges Didi Huberman, François Soulages- persiste una noción de huella y de traza, no semiótica, que percibe el destello, el relámpago que deja la imagen y su capacidad de reunir elementos dispersos.

Este cambio de paradigma ha recibido en los últimos años diversas denominaciones: postfotografía, infografía y otros. De todos, resulta interesante la opinión del estudioso Geoffrey Batchen que considera que se debe hablar de un "más allá"/beyond de la fotografía, concibiendo así una tecnología híbrida que se apropia de las especificidades discursivas de los dispositivos analógicos. En esta hibridez se alcanzan a entrever imágenes realistas, hiperrealistas y ficcionales. Si bien muchos autores sostienen que la fotografía nunca fue auténticamente real, sino que estuvo desde un principio basada en formas más o menos directas de simulacro, esto se ha agudizado en virtud de las escenificaciones de las que hoy la fotografía es objeto. Se aprecia por tanto un énfasis en la construcción, fabricación, forzado y escenificación de la imagen. Los trabajos ya no son juzgados en términos de verdadero o falso, sino de credibilidad, un pasaje del concepto de veracidad a uno de verosimilitud.

Es dable mencionar además, los cambios producidos por la preeminencia de internet, de las redes sociales y de la telefonía móvil. Resulta evidente entonces el gran impacto que ha producido la tecnosfera al instaurar una articulación diferente entre los procesos simbólicos que hacen a la producción y distribución de la visualidad actual ${ }^{1}$.

Por otra parte, cabe señalar que la imagen resulta un elemento objetivador del escenario circundante. Por un lado, objetivador pero también, adjetivador: las imágenes pueden tratar de mostrar (según distintos puntos de vista), convencer, seducir o representar hiperrealidades. Justamente por eso, proceden en ocasiones por intromisión y resultan instituidoras. Su cualidad enigmática provoca el pensamiento. El escritor contemporáneo Byung Chul Han diagnostica que huimos hacia las imágenes porque percibimos la realidad como imperfecta (2015, p. 52). 
Por otra parte, otro rasgo del desplazamiento ocurrido es la posibilidad de la imagen de integrarse, fusionarse junto a otros lenguajes. La enunciación realizada a través del nexo entre distintos lenguajes contiene una poiesis en cruce que posee sus propias lógicas tanto hacia adentro como hacia fuera. La lógica resultante da clara muestra de la complejidad de un discurso estético pero también de la complejidad del objeto que aborda. Resultan así "(...) focos enunciativos que instauran nuevos clivajes entre otros adentros y otros afueras y que promocionan un distinto metabolismo pasado-futuro a partir del cual la eternidad pueda coexistir con el instante presente"(Guattari, 1996 p. 112). La combinatoria de lenguajes conforma pues, interfaces que dan cuenta y acortan la brecha entre la exterioridad y la interioridad, provocando precisamente un ensanchamiento de los puntos de vista al establecer una red de vínculos, una extimidad materializada en un espacio topológico. Cabe agregar que en la combinación de lenguajes -en tanto coalescencia- se producen mezclas sensoriales y semióticas que convocan a nuevos modos de subjetivación.

Para atender otro aspecto del deslizamiento mencionado, se encuentra el concepto de estética a la vez que se halla en el libro Estética de la fotografía de François Soulages y que contribuye con precisión a la lectura de la fotografía contemporánea en tanto recupera "las fuerzas infinitas de la obra" (2005, p. 223) y puede ser utilizada incluso como rúbrica de análisis en virtud de que coadyuva a la lectura de la fotografía actual. La imagen se abre así a nuevos sentidos y la estética a la vez promueve justamente la articulación de lo real con lo imaginario ya mencionada.

De este modo, la fotografía contribuye a comprender tanto la historia como el devenir y el accionar contemporáneo. En términos de Soulages, la realización de imágenes parte de búsquedas técnicas y de sentido a la vez. Como integrante del lenguaje visual este dispositivo reflexiona sobre diversos tópicos: lo público, lo privado, lo psicológico, lo político, lo histórico, lo contemporáneo e instituye finalmente la historia de la imagen de cada colectivo. La imagen supone pues una operación social en base a la impresión de sentidos y es la constituyente primera, polimorfa y plástica de la iconósfera, "a partir de la cual toda conciencia teje sus relaciones con el mundo y con el sentido" (Wunenburger, 2005, p. 32). Además los textos visuales contienen un "Ethos cultural", es decir una ética y una política de su momento, que convoca a su interpretación. Por ello la fotografía torna visible el resplandor del instante pasado y presente.

A su vez, como práctica discursiva, permite indagar sobre la elección de los modos de enunciación en virtud de que cada productor visual presenta distintos modos de aproximarse al lenguaje visual. A propósito es interesante la coincidencia de criterios de Boris Groys como filósofo contemporáneo y lo desarrollado entre los años '70 y '90 por el pensador argentino Carlos Cullen (1987, p. 15). Ambos proponen que la cuestión del sujeto no debe diluirse en un discurso de no subjetividad sino que ese mismo discurso debe incorporar otras subjetividades. Cullen considera la existencia de una dialéctica en la que aparecen las operaciones de marcar y borrar las rúbricas espaciales y temporales. En este sentido resulta oportuna la siguiente estrofa de Jorge Luis Borges:

Un hombre se propone la tarea de dibujar el mundo. A lo largo de los años, puebla con imágenes de provincias, de reinos, de montañas, de bahías, de naves, de islas, de peces, de habitaciones, de instrumentos, de astros, de caballos y 
de personas. Poco antes de morir, descubre que ese paciente laberinto de líneas traza la imagen de su cara.

A partir de este fragmento se puede agregar la siguiente frase de Groys: "el campo del arte representa y expande la noción de sociedad, porque incluye no solo a los vivos sino también a los muertos e incluso a los que todavía no nacieron" (2014, p. 19).

El estatuto extático de la producción artística se debe pues a que revela verdades de un modo diferente, de alguna manera, trascendente. Si se considera a la realización estética como la manifestación sensible de la idea (Hegel) y como poiesis del destino histórico del ser (Heidegger) se arriba a la concepción de que se trata de la expresión de una fuerza vital a través de una praxis vital.

\section{Síntoma}

Tal y como ha venido ocurriendo a lo largo de toda la edad moderna es muy probable que también hoy los rasgos más relevantes de la existencia, y del sentido de nuestra época, se enuncien y anticipen, de manera particularmente evidente, en la experiencia estética.

Gianni Vattimo (1990, p. 133)

La posmodernidad, fenómeno que comienza hacia fines de los años ' 60 , producto de una sociedad postindustrial y que fuera tan bien descripta por Fredric Jameson es sucedida luego, por la caída del muro de Berlín en 1989 con la consecuente aparición del fenómeno de globalización que, a su vez, trajo aparejado un multiculturalismo tendiente a una hibridación cultural. Se puede advertir asimismo un tercer momento, el de una fluidez, fruto de la desterritorialización que el capitalismo promueve, y que presenta rasgos múltiples. Por eso, se adhiere al concepto de "vanguardias simultáneas" de Andrea Giunta (2014) en tanto diversidad de producciones como resultado del abordaje de variedad de temas.

A partir de este esbozo, se observan dentro del campo artístico negociaciones fronterizas entre lo excluido y lo admitido. Para explicar esta característica, Nicolás Bourriaud (2015, p. 11) utiliza el término exforma como el que designa la forma atrapada en un procedimiento de exclusión o inclusión como así también a los signos que se despliegan entre el centro y la periferia y que flotan entre la disidencia y el poder.

El arte es -y siempre ha sido- el lugar donde se hallan las preguntas, los cuestionamientos, las dudas, las incertidumbres. Estas características resuenan hoy más que nunca. Se advierte pues una heterocronía ya que se observan prácticas estéticas que utilizan las herramientas informáticas de búsqueda para poner en co-presencia diferentes épocas y lugares. En tal sentido Boris Groys considera que la vida se concibe como un proceso puramente material, no-teleológico y agrega que es justamente sobre esa materialidad que el arte opera, tanto para su conocimiento como para la percepción de su devenir (2016, pp. 46 y 47). Entre 1924 y 1929 Aby Warburg desarrolló su proyecto inconcluso Atlas Mnemosyne. Este proyecto mostraba su modo de agrupar una heterogénea serie de imágenes. Por esos años, Walter Benjamin, conocedor del proyecto, establece un método que se relaciona con el de 
Warburg, el de un montaje en función de asociaciones e interacciones, es decir, del desciframiento de síntomas, en tanto expresión de un malestar, de aquello que no funciona de acuerdo con un discurso determinado temporal y espacialmente. Entonces, para Benjamin, gracias a este desciframiento se puede "cepillar a contrapelo la historia".

Por su parte Alain Badiou identifica que a partir del siglo XX comienza una "pasión de lo real" que se desarrolla antagónicamente, donde destrucción y fundación aparecen simultáneamente (2011, p. 59). Y, Hal Foster en El retorno de lo real coincide sobre un deseo de reflexión por parte de los productores acerca de temas políticos y sus debates. Realiza asimismo un análisis sobre el deslizamiento contemporáneo -pero también una simultaneidad- de la producción como ventana a/ y la producción como texto (2001, p. 203). En este sentido Jacques Rancière identifica que cierta estrechez del espacio público y una merma en la imaginación política, producto de la caída de los grandes relatos y de la aparición de consensos, le otorgaron a las producciones artísticas y a las tecnológicas (o a sus combinaciones) una función sustitutiva a la que califica como una "práctica del disenso" (2011, p. 120). En esta línea se puede agregar la afirmación de Pierre Bourdieu sobre que los partidos políticos, los sindicatos, etc. "tienen un retraso de tres o cuatro guerras simbólicas" (1994, pp. 14-24).

Los dispositivos visuales (en tanto protagonistas de nuestra cultura visual, herramientas del arte contemporáneo y dadores de una pensatividad), pueden sorprender, desconcertar y sobre todo interrogar. Es por esto que la imagen se hace cargo en muchas ocasiones de las preocupaciones políticas y sociales presentes y responde a la interrogación planteada por Soulages: “¿puede haber proyectos y objetos fotográficos que a la vez interroguen a la sociedad y lo político y trabajen desde el sitio de arte?” (op.cit, p. 232). Tal vez la respuesta la tengamos en un pensador argentino llamado Rodolfo Kusch: "(...) el arte es una solución para un aspecto fallido de la existencia” (1955, p. 782).

Por ende, la producción estética enuncia de acuerdo a lo planteado pero también a través de una dualidad dentro de la estructura temporal del acontecer: como marca de la historia pero a su vez como una interrupción, como un pliegue del devenir. De este modo, dentro del terreno estético, se evidencia un deslizamiento metonímico del deseo de comprensión y transformación de la realidad. Se advierte entonces un lazo entre política y arte que se traduce en un vínculo entre el hecho y la forma. Al mismo tiempo, se considera oportuna la unión entre discurso y forma. Así, lo estético no solamente no forcluye el principio político sino que lo potencia, a partir de una actitud insurgente. En este aspecto se puede agregar que Benjamin en su conferencia "El autor como productor" indicaba no separar la forma y el contenido y agregaba "El concepto de técnica depara el punto de arranque dialéctico desde el que superar la estéril contraposición de forma y contenido" (1975, p. 119). A su vez, Nicolás Borriaud indica: "El arte es pues una especie de banco de montaje salvaje, que capta la realidad social por la forma” (2009, p. 114). Así, las obras producen la ficción de un universo que trabaja sobre lo real, lo imaginario y sobre lo simbólico. Cabe añadir que se aprecia también la existencia de una característica enunciativa que privilegia el concepto y la narración.

Dentro de esta exploración sobre la imagen como síntoma se debe considerar las imágenes ausentes. Ausentes por temas no abordados, ausentes que en algún momento existieron pero que ya no se hallan o no se miran. Ausentes por haber sido prohibidas, censuradas y 
tal vez destruidas. Se halla entonces un espacio intersticial entre lo que es dado a ver y lo que no.

Se encuentra también hoy un deseo de recuperar la cosa misma (presentación) frente a la representación que se encontraba en las distintas producciones. Existe pues un ideario que considera que la presentación asegura una especie de transparencia por encontrarse circunscripta a un presente. La noción de aletheia heideggeriana como idea de desocultación comprende una lógica de visibilización de lo no visible. De algún modo, dentro de la actividad estética como producción simbólica, la elección de la presentación adhiere al siguiente pensamiento de Baudelaire: "extraer la eternidad de lo transitorio" (en Bourriaud, 2009 , p. 105). A propósito, Sigfried Kracauer sostenía que la posibilidad de la fotografía no es solo reproducir un objeto dado sino su capacidad de separarlo de sí mismo (en Cadava, p. 39). En esa separación se crea un espacio intersticial en donde se presenta, se exterioriza el síntoma. Las imágenes por su carácter de inscriptores de sentido, dan cuenta del síntoma y coadyuvan a una mirada crítica y/o redentora de lo real, según sea el caso, pero siempre colaboran con su hermenéutica.

La imagen se coloca así entre lo sensible y lo inteligible produciendo un relevamiento de los síntomas. La imagen interrumpe el curso normal de la representación, muestra el aspecto inconsciente y permite desplegar sintagmáticamente la función poética y emotiva que subyace detrás de cualquier discurso. En ocasiones la estética a la vez, ya mencionada, se encuentra determinada por un lado, a interrogar las tensiones y relaciones de lo real y, por otro, a desarrollar lo simbólico. El realizador visual se encuentra además, ante la dicotomía de mostrar lo real -hasta el punto de convertir las imágenes en documentos- pero, al mismo tiempo, de descubrir también lo privado, lo interdicto de cada caso relevado. En ocasiones se conjuga al mismo tiempo, lo documental con lo autoral.

De este modo, los productores se convierten en verdaderos "espigadores" 3 que crean narrativas a partir de procesos intertextuales como la trasposición, la apropiación, la parodia, la cita. A su vez, las metamórficas se apoyan sobre cierta indiscernibilidad, en ocasiones relatan algo pero de otro modo, establecen distintas relaciones para arribar a una especie de interdefinibilidad.

La imagen se presenta también como generadora de relatos, como señaladora, indicadora, capaz de instaurar relaciones. Se trata, al decir de Benjamin, "de levantar las grandes construcciones con los elementos constructivos más pequeños (...) Descubrir entonces en el análisis del pequeño momento singular el cristal del acontecer total" (en Didi Huberman, 2015, p. 18).

En las diferentes modalidades, desde el orden de lo simbólico, la imagen síntoma tiene una significación que invita a ser descifrada, como un enigma a resolver.

\section{Gesto}

(...) Las emociones tienen un poder de transformación. Transformación de la memoria hacia el deseo, del pasado hacia el futuro o bien de la tristeza hacia la alegría. Georges Didi Huberman (2016, p. 53) 
Para desplegar los aspectos del gesto productor, se partirá de la consideración de Julia Kristeva en tanto que el lenguaje demarca, significa y comunica, agregándole el pensamiento del filósofo Gilles Châtelet, quien sostenía que "el pensamiento está enraizado en el cuerpo" y agregaba "Todo pensamiento es el anudamiento de un espacio y un gesto (...)" (en Badiou, 2009, p. 156-157). Ya se ha mencionado la consideración de Walter Benjamin acerca de la percepción de un inconsciente óptico del mismo modo que el psicoanálisis permite percibir el inconsciente pulsional. Justamente, este autor hizo referencia así a Freud en su búsqueda por identificar el pasaje del inconsciente a la conciencia para la cual realizó analogías con medios técnicos. En "Nota sobre el inconsciente" el psicoanalista estableció una correspondencia con el pasaje del negativo al positivo. Tanto el inconsciente como el negativo están conformados por un entramado de trazos a la espera de su revelado. La cámara, a través del gesto enunciador, representa entonces la condición de posibilidad de luz y de escritura. Es a partir de esta concepción, vinculada tanto a la producción como a la comunicación, que se desarrollarán algunos conceptos sobre la categoría de gesto.

Michel Foucault ha considerado que la enunciación ocupa un lugar fundacional y de vital importancia para entender al autor: "Analizar las positividades significa mostrar según qué reglas una práctica discursiva puede formar grupos de objetos, conjuntos de enunciaciones, juegos de conceptos, series de elecciones teóricas" (En Agamben, 2009, p. 20).

Se puede establecer que los dispositivos, integrantes del lenguaje visual, como la fotografía, el cine y el video circunscriben mediante el gesto del encuadre y resultan productores de una semiosis. Esta semiosis, a su vez, trata de ser comunicada a un receptor por medio de una sintaxis. Por ello se adhiere a la concepción foucaultiana de práctica discursiva, en la cual la enunciación ocupa un lugar fundacional. Este autor destaca que las prácticas discursivas son sistemas que crean significados culturales a partir de la subjetividad del enunciatario. Además, el discurso, es una instancia de análisis donde la enunciación no puede ser disociada de su enunciado. La enunciación entendida, entonces, como el conjunto de condiciones presentes en la producción de un mensaje, es decir, una enunciación que parte de la individualidad del enunciador pero, también, de su relación con la caracterización de la época tanto desde lo filosófico como desde el ámbito socio político y cultural en el que está inmerso.

Jacques Fontanille sostiene que enunciar es hacer presente cualquier cosa con la ayuda del lenguaje. De este modo, la enunciación constituye el universo de lo estético-artístico y, por tanto, se encuentra siempre presente en el interior de un enunciado (en Ducrot, Todorov, 2003, p. 367).

La enunciación se constituye pues a través de una urdimbre donde la referencia a lo externo es materializada desde una interioridad y la forma en que se va estableciendo la interacción entre ambos. Michel Foucault expuso en 1969 ante la Sociedad Francesa de Filosofía que la noción de autor individualiza la historia de las ideas, de los conocimientos, de la filosofía, de las ciencias y de las artes. El pensador francés relataba que hubo un tiempo en que los textos literarios eran, por ejemplo, puestos en circulación sin que se conociese su autoría, identificando solo diferencias entre autores de discursos científicos y aquellos de discursos literarios. Esto fue modificándose a partir de los siglos XVII y XVIII. A su vez, los análisis comunicacionales incorporaron dos aspectos que denotan y connotan la pre- 
sencia autoral: la función poética y la función emotiva. Ambas funciones delatan al autor como un individuo social y visibilizan sus competencias lingüísticas y culturales como así también sus determinaciones psicológicas e ideológicas. Tanto Mijail Bajtin como Fredric Jameson hacen referencia a esta última determinación con el nombre de ideologema. Al respecto, Bajtin sostenía:

(...) todos los productos de creatividad ideológica -obras de arte, trabajos científicos, símbolos y ritos religiosos- representan objetos materiales, partes de la realidad que circundan al hombre (...) no tienen existencia concreta sino mediante el trabajo sobre algún tipo de material... únicamente llegan a ser una realidad ideológica al plasmarse mediante las palabras, las acciones, la vestimenta, la conducta y la organización de los hombres y de las cosas (1994, p. 46).

De esta individualización forma parte el gesto anafórico (Kristeva, 1999, p. 121-125) es decir, señalar, indicar, mostrar e instaurar relaciones. Es importante recalcar entonces que se trata de una combinación cuerpo y palabra, lo consciente y lo inconsciente, lo abierto con lo denso, lo sencillo con lo complejo, siempre a través de una energía y vivacidad manifiestas.

De este modo, se comprende por gesto la "torsión hecha de afectos y de pensamientos" (Kristeva, 1980). Se puede añadir en este sentido la consideración de Jean Paul Sartre de que la emoción es un modo de aprehender el mundo y, de Maurice Merleau Ponty, que la caracteriza como una suerte de conocimiento sensible de transformación activa del mundo.

En los procedimientos del lenguaje visual se puede percibir la elección de qué incluir y qué dejar afuera. Se encuentra en este gesto una dialéctica entre atracción y retracción; el creador se ve atraído a insertar cierto fragmento y a descartar otro en tanto develamiento. El gesto implica así un acto demarcado por el deseo. Las categorías de espacio y de tiempo, atributos inherentes al lenguaje que nos ocupa, conforman, tal como lo expresara Immanuel Kant, la estructura espacio/tiempo en el pensamiento humano para relacionarse con el mundo. El productor visual al realizar este recorte remite existencialmente a algo. Otro gesto que se puede identificar en el lenguaje visual es el de la hendidura, entendido como un proceso de profunda introducción en un tema a través de un tajo, de un corte. Por todos estos aspectos cabe señalar que en el gesto de toda producción estética se halla también un vínculo entre juego y conflicto.

Un atributo a considerar es el asombro. El productor posa una mirada sobre las cosas, descubriéndolas (a pesar de su aparente banalidad) y asombrándose de ese descubrimiento. Ese asombro tiene algo de intempestivo porque en él se encuentra la sorpresa del hallazgo. La captación visual produce un efecto de nuevo, de nunca visto de algo que en realidad suele poder reconocerse.

A su vez, a través del gesto, el productor conjuga lo exterior con lo interior, territorializando o desterritorializando según sea el caso y agenciando niveles, intensidades y duraciones. Por eso, exponer en cualquier dispositivo, en tanto práctica, no es solamente expresar un pensamiento, implica un modo de revelación que nos devuelve a la experiencia, ya sea a 
la experiencia de asomarnos a lo Real o a la experiencia de la escenificación y del relato. También a la experiencia de la exposición de las decisiones poéticas frente a la mirada del receptor, al que se le convoca, según Foucault en virtud de que: "lo propio del saber no es ni ver ni demostrar, sino interpretar" (2014, p. 58).

Georges Didi Huberman comprende que las imágenes son una especie de cristales en las cuales se concentran muchas cosas, entre ellos los gestos. (2016, p. 42) Es pues donde se revela el pathos desde la praxis. En los detalles menos intencionales aparece la traza del autor, dando cuenta del "residuo de la observación" enunciado por Sigmund Freud. (en Bourriaud, 2015, p. 86). Pero, además, en la contemporaneidad se aprecia una clara intención por mostrar lo que se puede llamar "residuo de la enunciación" en tanto clara visibilización de las marcas en que fue elaborado el discurso. En ciertas producciones ligadas a la escenificación se puede apreciar una clara artificialización que permite entrever las diferentes estrategias utilizadas o las dislocaciones narrativas realizadas.

Se aprecia asimismo en la actualidad enunciaciones colectivas, es decir, autorías grupales, en las que intervienen colaboraciones interdisciplinarias, colaboraciones maquínicas, científicas, informáticas y otras. El proceso creativo tiene entonces implicaciones éticopolíticas en donde se distingue un compromiso con la instancia creativa y que garantiza el derecho a la singularidad.

\section{El relato contemporáneo}

(...) El proceso de composición, de configuración, no se realiza en el texto, sino en el lector, y bajo esta condición, posibilita la reconfiguración de la vida por parte del relato. Más exactamente diría que el sentido o el significado de un relato brota en la intersección del mundo del texto con el mundo del lector. Paul Ricoeur (1984, p. 51)

A partir de la caracterización realizada del gesto productor se puede agregar, en las opciones narrativas, el gesto de enlazar, el gesto del montaje. En el montaje se articulan elementos, se los vincula y se otorga sentido.

A pesar de la desmaterialización desde el advenimiento de la tecnología digital y sus posibilidades de una rápida circulación y consumo ya comentada, el fotolibro resulta un fenómeno creciente que contradice la existencia de una única vía de comunicación inmaterial. El fotolibro nace del libro de artista. El libro de artista es una obra de origen conceptual que, a través de un accionar pensado, aúna en ocasiones la imagen y la palabra. El denominado "giro lingüístico" tuvo gran incidencia en la emergencia y el desarrollo del arte conceptual. Justamente, el libro de artista obtiene un sitio dentro de la producción artística en una época en que el arte conceptual y el arte intermedia comenzaron a desplegar su influencia. Ulises Carrión también contemplaba al libro de artista como una obra conceptual y por eso exponía en El nuevo arte de hacer libros (1980): "Un libro es una secuencia de espacios. Cada uno de esos espacios es percibido en un momento diferente: un libro también es una secuencia de momentos". 
Desde su concepción, alberga también las variables comunicacionales. Se puede identificar al libro de artista como una obra de cruce de lenguajes ya que se pueden observar en él los pliegues y despliegues de sentido.

Los elementos constitutivos que integran un libro de artista conforman códigos que, interrelacionados en conjunto, configuran un discurso. En tal sentido, Mijail Bajtín señala como "componente estético" de una obra a la forma en la que es configurada (ya sea tan solo imágenes o su combinación con texto) y en donde se hallan implicados también los procesos psíquicos de creación y recepción.

Como obra de cruce presenta un carácter de homeomorfo, es decir una transformación topológica que implica correspondencia y continuidad.

La siguiente frase de Giles Deleuze puede ser aplicada a la noción de libro de artista: "Plegar-desplegar, envolver-desarrollar son las constantes de ésta operación hoy en día como el Barroco. (...) Incluso comprimidos, plegados y envueltos, los elementos son potencias de ensanchamiento y estiramiento del mundo" (1989, p. 157).

La historia de la fotografía tiene antecedentes muy tempranos: El descubridor de la reproductibilidad, Henri Fox Talbot, creó entre 1844 y 1846 un álbum denominado The pencil of nature de seis ejemplares donde intentaba mostrar las maravillas naturales y realizadas por el hombre del mundo. Por su parte Ana Atkins realizó fotolibros entre 1843 y 1854 con la técnica del cianotipo llamados British Algae: Cyanotype Impressions donde mostraba una gran variedad botánica. En los años de constitución de las diferentes naciones latinoamericanas, los álbumes de los fotógrafos viajeros (con una mirada puesta sobre lo exótico y lo pintoresco) más los realizados por los fotógrafos coterráneos (con un deseo de dar cuenta del crecimiento), conforman una memoria narrativa.

En el fotolibro las decisiones que se deben tomar en su concepción coinciden con las del libro de artista en la mayoría de los casos y en otros no. Coincide la dilucidación del diseño, el tamaño y la encuadernación. Asimismo el desarrollo de la narratividad, todo debe dialogar entre sí (las imágenes una con otra, el texto uno con otro, imágenes y textos, etc.). Lo diferente es la cantidad, la elección del papel (difícil por la variedad) y donde y cuantos ejemplares se van a imprimir. Asimismo la tipografía. En el fotolibro aparecen otros actores y no solamente el autor: tal vez un diseñador gráfico, la imprenta e incluso, en caso de tiradas grandes, él encargado de la distribución.

Resultan también proyectivos, ligados a la praxis fotográfica, en virtud de que actualmente varios autores determinan muchos aspectos de su trabajo fotográfico pensando a priori en una publicación impresa. En ese sentido el fotolibro está ligado a la industria y al mercado. Dentro de estas dos rúbricas se encuentra la característica de la autoedición. Por ello, hay autores fotográficos que lo consideran ubicado intersticialmente entre la literatura y el cine. Joan Fontcuberta ha manifestado que "Si la fotografía es básicamente huella y descripción, el libro le permite desplegar toda su sintaxis" (2011). El cultor del fotolibro para su propia obra y patrocinador de la realización de los mismos, Martin Parr lo considera una obra en sí misma y añade que para ello debe encontrarse una estrecha relación entre las ideas, las imágenes y la forma. A través del gesto de montaje, de enhebrado de foto a foto, página a página, el productor visual despliega su propuesta artística.

En ocasiones se pueden apreciar procesos alegóricos que presentan una vocación de sentido, de significación. En este sentido, Italo Calvino considera: “Decimos que es poética una 
producción en la que cualquier experiencia singular adquiere evidencia destacándose de la continuidad del todo pero conservándose como un reflejo de aquella vastedad ilimitada" (1989, p. 8).

En todos los casos, cabe también detenerse en la figura del receptor. Se trata de un receptor atento que tiene un contacto directo con el objeto. Un contacto que implica un acercamiento diferente a otro tipo de obra. Un contacto que implica también la noción de tiempo. Un tiempo personal, los instantes que le lleva recorrer el contenido, el paso de página a página. Podríamos decir entonces que se trata de una producción verdaderamente relacional.

El relato contemporáneo se halla conformado también por la integración de la imagen en performances (en donde se advierte un gesto proxémico) y en instalaciones. Al respecto Ticio Escobar señala que el recurso de la performatividad empuja el discurso hacia afuera en donde se consideran las condiciones de enunciación, su impacto en el receptor, su inscripción histórica, su densidad narrativa y su dimensión ética.

Por su parte, Groys considera que la instalación como forma de arte está conectada de manera evidente a la repolitización del arte. La instalación es recorrida por un receptor flâneur que recorre una disposición diseñada por el productor de, en general, una combinatoria de lenguajes y que se ordenan alrededor de una narrativa que apunta a un sentido particular. De este modo, la instalación le ofrece a este receptor paseante un aura de "aquí y ahora".

\section{La imagen como área de trabajo}

Este apartado está destinado a reflexionar sobre la importancia de la puesta en relación, es decir sobre la problemática de uso, a través de la figura del receptor como sujeto activo dentro del circuito comunicacional. El análisis de la imagen debe ser realizado, no sólo a partir de sus particularidades estéticas, sus condiciones de producción (las condiciones de posibilidad para su aparición están conformadas por la deliberación temática, la elección de los materiales, la puesta en acto de los presupuestos ideológicos, socio-políticos y culturales, es decir, todo lo que forma parte del gesto analizado más arriba) y su recepción. Por otra parte cabe destacar que en la actualidad ya no se aprecia una oposición tan tajante entre arte autónomo e industria cultural como cuando ésta última nomenclatura apareció en los escritos de Theodor Adorno y de la Escuela de Frankfurt.

Se analizará entonces la puesta en relación desde la recepción y desde la educación visual. Por ello, verbos como construir, tejer, pegar, conjugar serán puestos en correlación.

\section{Acerca de la recepción}

En el circuito comunicacional que atraviesa un mensaje estético se produce una transferencia de subjetivación entre el productor y el receptor.

En la contemporaneidad la recepción se encuentra atravesada por la reflexión acerca del contexto de la producción de la obra, de su distribución y emplazamiento, de su eficacia de comprensión y de la afluencia del público (según Boris Groys esto ya fue anunciado por Marx y Engels en el libro Ideología alemana (2016, p. 95). 
A propósito del emplazamiento, se puede citar como ejemplo la video-instalación denominada Algunas viudas de Noirmoutier que realizara Agnés Varda en el año 2005 y que fuera expuesta ese mismo año en la Galería Martine Aboucaya y al año siguiente en la Fundación Cartier de Paris. Mediante 16 pantallas se podían apreciar dieciséis entrevistas realizadas a viudas residentes en la isla de ese nombre cuya principal actividad es la pesca. Ella misma era la número diecisiete. Durante la entrevista cada viuda mostraba una fotografía en la que se la podía ver junto a su marido. En este caso, el espectador miraba las pantallas pero, para acceder al audio, debía sentarse en alguno de los dieciséis asientos con un auricular cada uno. Si estaba interesado en escuchar las anécdotas de cada viuda debía rotar entre los asientos ya que cada auricular albergaba la historia de una. Agnés modificaba así el pacto contractual cinematográfico habitual.

En este sentido, Roman Jakobson establece que cuantos más conocimientos posea el receptor del código utilizado por el emisor, mayor será la cantidad de información que éste podrá obtener, haciendo así directa alusión a las competencias lingüísticas y culturales del destinatario. Se considera hoy también la noción de experiencia o de acontecimiento en tanto impacto en el receptor. Justamente Hans Georg Gadamer hablaba de "fusión de horizontes" en tanto unión del horizonte de expectativa que un texto presenta y el horizonte de la experiencia.

(...) en la experiencia del arte, se trata de que aprendamos a demorarnos de un modo específico en la obra del arte. (...) Cuanto más nos sumerjamos en ella, demorándonos, tanto más elocuente, rica y múltiple se nos manifestará. La esencia de la experiencia temporal del arte consiste en aprender a demorarse (1998, pp. 110-111).

Epistemológicamente, la experiencia está ligada a la percepción y a la sensación. En la filosofía platónica se establecía una diferencia entre el mundo sensible y el mundo inteligible. Francis Bacon sostenía que la experiencia es, no sólo el punto de partida del conocimiento, sino su fundamento último. Por su parte, Kant, al igual que los pensadores empiristas, consideraba que la experiencia constituye el inicio del conocimiento. A partir de lo indicado, el espectador no solo mira sino también se siente alcanzado por lo que Kant llamara "una rapsodia de percepciones" (en Agamben, 2009, p. 38) y de experimentar así una sensación encontrando una coincidencia entre lo subjetivo y lo objetivo, entre lo interno y lo externo, entre lo sensible y lo inteligible.

$\mathrm{Al}$ respecto, Umberto Eco planteaba:

Desde las estructuras que se mueven hasta aquellas en que nosotros nos movemos, la poética contemporánea nos propone una gama de formas que apelan a la movilidad de las perspectivas, a la múltiple variedad de las interpretaciones. Pero hemos visto igualmente que ninguna obra de arte es de hecho "cerrada", sino que encierra, en su definición exterior, una infinidad de "lecturas" posibles (1992, p. 48). 
Louis Marin coincide con este pensamiento ya que plantea que la lectura nunca es estática ya que se trata de un "sistema abierto de fuerzas en constante y perpetua recomposición" (1978, p. 53). En todos los casos, la noción de contexto (en sus variables cronotópicas) también forma parte de los indicadores de lectura. A propósito, Adolfo Sánchez Vázquez señala justamente los cambios que han producido las tecnologías en la recepción estética. La percepción produce una deictización del espacio, establece parámetros espaciotemporales. Esta deictización opera pues sobre las categorizaciones semánticas del espacio cultual que el receptor percibe en combinaciones tales como lo público y lo privado. Así el espectador es convocado a una mirada que descubra mucho más allá de lo que se muestra y que perciba la irradiación que toda obra pretende convocar.

Se comprende entonces que se hallan -y se buscan-comunidades interpretativas creadoras que establezcan pactos de lectura, de comprensión, de sensibilidad que posibiliten una acción. La puesta en escena de un "proyecto comunicativo" (Eco, op.cit., p. 59) trata de convocar a un espectador que busque no solo lo expuesto a su visión sino que establezca relaciones, que se plantee interrogantes, que complete lo faltante acerca de las tensiones individuales e históricas. A propósito, Didi Hubermann considera que es necesario "rearmar los ojos" para ver, intentar ver y reaprender a ver. De hecho, propicia oponer el poder de la mirada por sobre el poder de las imágenes (2015, pp. 104-105).

La esfera estética ya no es simplemente contemplada, es sometida entonces a diferentes miradas vivaces. En este punto es interesante considerar la opinión de Ticio Escobar cuando expresa: "Quizá todo se reduzca a una operación de administrar distancias, de aplicar políticas eficaces de la mirada” $(2015$, p. 13).

\section{Relato didáctico}

La historia del lenguaje visual no es un archivo inmóvil de imágenes, se trata de un repertorio de "gestos de la humanidad" (Agamben, 2001, p. 51) en permanente movimiento interpretativo y que incide directamente sobre el devenir. Además, el imaginario se encuentra conformado por la circulación de las imágenes que ya existen en el mundo. Por todo eso resulta tan importante atender dos aspectos didácticos diferentes: por un lado una alfabetización visual y, por otro la didáctica específica. Ambos casos deben atender cuales son los aspectos que se tornan visibles en una imagen y qué representaciones se pueden detectar en cada una.

Con respecto a la alfabetización, Lazlo Moholy Nagy indicaba:

El prerrequisito para esta revelación es, desde luego, darse cuenta de que el conocimiento de la fotografía es tan importante como el del alfabeto. Los analfabetos del futuro serán aquellos que ignoren el uso de la cámara y de la pluma (en Fontcuberta, 2003, p. 195).

En pedagogía se introduce hoy el término de multialfabetizaciones (formulado por el New London Group alrededor de 1996) que alude a la necesidad de formar al alumnado en las distintas alfabetizaciones que conforman su realidad contemporánea y de las cuales la tecnología y la visualidad forman parte. 
Por su parte, la didáctica específica debería estar compuesta por una atenta contemplación en términos filosóficos y una teoría tendiente a la práctica, a la acción vital. En este sentido se identifican varias producciones estéticas como acciones vivaces que dieron cuenta de un saber, por ejemplo: Kandinsky reconocía su giro hacia la abstracción a partir de la teoría de la relatividad de Einstein, el constructivismo ruso reflejó las tendencias políticas de la teoría marxista, el surrealismo articuló con la teoría del inconsciente de Freud y, posteriormente el arte conceptual tuvo un correlato con las distintas teorías del lenguaje. En la actualidad, se identifican, entre otros, las manifestaciones artísticas que responden a la preocupación por el Antropoceno ${ }^{4}$.

A su vez se aprecia la concepción de que los distintos lenguajes (entre el que se encuentra desde su aparición, el visual) son una forma de conocimiento y como tal su decodificación hermenéutica debe ser emprendida. En tal sentido, una didáctica -conforme a las necesidades contemporáneas- del lenguaje visual está en condiciones de romper con la dicotomía de una didáctica general más próxima a las teorías del pensamiento y a los procesos de cognición mientras que la específica se encuentra ligada a la práctica. En consecuencia, ambas didácticas deben coordinarse en un esfuerzo teórico-práctico (Camilloni, 2007). Una teoría le abre las puertas al conocimiento, es un punto de partida y no de llegada y es, a su vez, la condición de posibilidad de tratar un problema. Esta multiplicidad se manifiesta además en el diseño visual al formar parte de una disciplina proyectual que se enriquece con la interacción con otras disciplinas.

La relación entre la teoría y la práctica presenta una gran complejidad en la formación universitaria en virtud de la diferencia que existe entre esa institución y una escuela artesanal. Se tratará pues de visualizar ambos componentes didácticos de una manera integral, en la cual las dos se fortalezcan a través de una interacción. La teoría se constituye en un permanente recurso para la práctica y juntas resultan la condición de posibilidad de un conocimiento consciente y pleno que contribuirá a que el día de mañana el futuro profesional pueda insertarse -dentro de su especialidad- en distintos campos.

Es una buena ocasión de establecer qué consideramos teoría. Tal vez sea interesante recordar que un manual de uso es un elemento teórico. Lo mismo sucede en las clases que comunican variables técnicas. En cualquier ocasión emplear algunas estrategias para asegurar un aprendizaje significativo resultan convenientes. Una de ellas es la del relato.

Vladímir Propp elaboró una teoría en torno a la narración que podemos aplicar en el aula para los análisis teóricos: Realizar una puesta en común de posibilidades para encontrar juntos la trama, el nudo de una teoría. A pesar de que algunas teorías componen una totalidad, las mismas se pueden secuenciar. Las secuencias se pueden entrelazar y se pueden suceder una después de la otra. Tornar inteligible algo implica elegir, ordenar, ligar aspectos y fragmentos. La conclusión es una oportunidad didáctica a la que pueden arribar juntos en clase todos los integrantes del acto educativo. Asimismo se puede trabajar una teoría (una pieza, un autor) como protagonista y oponerle otra como antagonista.

En realidad la búsqueda está puesta en "experimentar" el aula. La revelación, en tanto descubrimiento intelectual y emocional, conduce a la experiencia que impacta directamente sobre lo inteligible y lo sensible. Una de las formas de unión es durante las correcciones de las distintas imágenes o piezas de diseño recordar algunas consideraciones teóricas vistas en la clase. Cuando se completa la experiencia con un sentido teórico se posibilita el me- 
joramiento de las prácticas. Como se ha mencionado en escritos anteriores, Lev Vygotsky manifestaba que "Cuanto más rica sea la experiencia humana, tanto mayor será el material del que dispone esa imaginación".

Por otra parte, es dable recordar que el poder, el impacto y la significación de la imagen cobran sentido recién cuando pueden ser verbalizados. Su verdadero valor de transformación se libera cuando una está atravesada por la otra. Michel Foucault hablaba (en una entrevista que le hiciera Gilles Deleuze en 1980) de acción de teoría y de acción de práctica a lo que podemos sumarle palabras como conexiones, empalme, red e imbricación. Cabe mencionar entonces la siguiente recomendación de Marta Souto "La formación de un hacer pensante, ni hacer ni pensamiento aislados, sino en conjunto y coproduciéndose" (Souto, 2016, p. 169).

Se considera a la instancia educativa como un trabajo colaborativo entre docente y alumno en el cual -juntos ${ }^{5}$ - construyen el saber en tanto interés y pasión. Es por eso que se cree en una potencia instituyente y no en una instituida. A tal efecto, la institución educativa no debe ser solo un lugar de trasmisión de conocimientos sino de resubjetivación, de sensibilización. Al trabajar con la imagen estamos trabajando con aspectos simbólicos que inciden sobre el imaginario individual y colectivo.

Por eso se alienta realizar un análisis de la imagen que comprenda la relación forma y contenido/forma y significación. Sumergirse en una imagen o serie de imágenes desde estas categorías de análisis enriquece el discurso y abre las puertas para profundizar sobre las posibilidades que cada imagen brinda. Se sugiere a tal efecto las reflexiones del pensador de arte contemporáneo Nicolás Bourriaud en sus libros, Ex forma, Posproducción, Radicante y Estética Relacional. En Radicante explicita: "El artista como semionauta pone las formas en movimiento, inventa a través de ellas y con ellas trayectos por los que elabora el corpus de sus obras" (p. 59).

El hincapié está puesto entonces en pensar la experiencia educativa como una heurística en la que el estudiante comienza a construir el mundo.

\section{Cierre y apertura}

A modo de cierre de este escrito pero de apertura a seguir reflexionando sobre la incidencia de los diferentes registros visuales se adhiere con lo escrito por Ticio Escobar acerca de que el arte permite vincular presencia y ausencia, desconocer sus propios límites, iluminar donde otras esferas fracasan y abrir, como ya se ha indicado, a "opciones políticas de la mirada" (op. cit., p. 15).

Así, todo lo vertido hasta aquí intenta señalar la emergencia de las imágenes en la contemporaneidad, marcada por diversos factores que, a modo de resumen, se pueden enunciar como su inmaterialidad, su disposición inmediata y transmisibilidad y finalmente su profusión. Sin embargo, este señalamiento es -al mismo tiempo- una propuesta y una apuesta a una imagen que siga develando los diversos síntomas de la actualidad, que sea realizada por un gesto comprometido y creativo (un tanto insurgente) y que apele a la sensibilidad y pensatividad del receptor. 


\section{Notas}

1. Este tema fue abordado con mayor detalle en "La distribución de lo inteligible y lo sensible hoy" en Polo Viviana, Niedermaier Alejandra (Eds) (2012) Acerca de la subjetividad contemporánea, Cuaderno no 43, Buenos Aires, Universidad de Palermo.

2. Eduardo Grüner alude a que la estética de un texto artístico está impregnado de la ética y la política de su momento histórico en la Introducción de Michel Foucault: Nietzsche, Freud, Marx, Buenos Aires, Ediciones El cielo por asalto, p. 11. Por su parte, Carlos Cullen considera que el ethos ubica éticamente lo social (...) en Reflexiones desde América, Fundación Ross, Rosario, 1987, p. 19.

3. Se toma este término a partir de las películas "Los espigadores y la espigadora" de Agnès Varda de los años 2000 y 2002. Varda comienza estas narraciones partiendo del amplio concepto de espigar en el que habitan verbos como recoger y recolectar. Verbos que conllevan un gesto con el que la directora construye su enunciado, incluyéndose ella misma como una espigadora, recolectora de imágenes, de momentos, de vivencias para mostrar los desgarramientos, los pliegues y las fisuras de un sistema económico, político y cultural. 4. Término que proviene de la geología para designar la era que abarca desde la invención de la máquina de vapor hasta el presente por encontrarse en ella huellas de la intervención humana sobre la tierra. Algunos pensadores contemporáneos diagnostican que el momento actual está caracterizado por una acumulación de capital que conlleva un deseo sin límites de incremento. De allí que el hombre se ha convertido en un agente de destrucción ya que no tiene en cuenta que sus acciones poseen una consecuencia directa sobre el medio ambiente. El concepto de antropoceno como peligro de extinción del planeta y de la humanidad deriva de la economía basada en actividades que afectan directamente a la tierra. 5. Se reitera el concepto "juntos" en varias ocasiones porque es el que mejor describe las distintas interacciones a las que se aspira en el accionar educativo.

\section{Referencias bibliográficas}

Agamben, G. (2009). Signatura rerum. Buenos Aires: Adriana Hidalgo.

Agamben, G. (2001). Medios sin fin. Valencia: Pre textos.

Badiou, A. (2009). Pequeño panteón portátil. Buenos Aires: Fondo de Cultura Económica.

Badiou, A. (2011). El siglo. Buenos Aires: Manantial.

Bajtin, M. y Medvedev, P. (1994). El método formal en los estudios literarios: Introducción crítica a una poética sociológica. Madrid: Alianza Editorial.

Bajtín, M. (1975). Teoría y estética de la novela. Madrid: Taurus.

Benjamin, W. (2007). Sobre el concepto de la historia, en Conceptos de filosofía de la historia. La Plata, Terramar Ediciones.

Benjamin, W. (1975). Tentativas sobre Brecht. Madrid: Taurus.

Bourdieu, P. y Haacke, H. (1994). “Efectos de librecambio”, Revista Mil palabras: Letras y artes en revista $n^{\circ} 3$.

Bourriaud, N. (2009). Radicante. Buenos Aires: Adriana Hidalgo.

Bourraiud, N. (2015). Ex forma. Buenos Aires: Adriana Hidalgo. 
Brassai (2001). Proust in the power of photography. The University Chicago Press.

Cadava, E. (2014). Trazos de luz. Buenos Aires: Palinodia.

Calvino, I. (1989). Bajo el sol del juglar. Madrid: Tusquets.

Camilloni, A. (2007). El saber didáctico. Buenos Aires: Paidós.

Cangi, A. (2011). "Poetizar sobre las ruinas entre la historia y el acontecimiento" en Godard Jean Luc Historia(s) del cine, Buenos Aires, Caja Negra.

Cullen, C. (1987). Reflexiones desde América. Rosario: Fundación Ross.

Han, B.-C. (2015). En el enjambre. Buenos Aires: Herder.

Deleuze, G. (1987). El bergsonismo. Madrid: Cátedra.

Deleuze, G. (1989). El Pliegue: Leibniz y el barroco. Barcelona: Paidós.

Didi Huberman, G. (2008). "La emoción no dice yo. Diez fragmentos sobre la libertad estética"en La política de las imágenes. Santiago de Chile: Ediciones Metales Pesados.

Didi Huberman, G. (2016). ¿Qué emoción! ¿Quéemoción?. Buenos Aires: Capital Intelectual.

Didi Huberman, G. (2014). "Vuelta-revuelta, Eisenstein, el pensamiento dialéctico frente a las imágenes" en AA.VV, Pensar con imágenes, Universidad Nacional Tres de Febrero.

Didi Huberman, G. (2015). Remontajes del tiempo padecido. Buenos Aires: FUC/Biblos.

Ducrot, O. y Todorov, T. (2003). Diccionario enciclopédico de las ciencias del lenguaje. Buenos Aires: Siglo Veintiuno.

Escobar, T. (2015). Imagen e intemperie. Buenos Aires: Capital Intelectual.

Eco, U. (1992). Obra Abierta. Barcelona: Planeta Agostini.

Fontcuberta, J. (2016). La furia de las imágenes. Barcelona: Galaxia Gutenberg.

Fontcuberta, J. (comp. 2003). Estética fotográfica. Barcelona: Gusavo Gili.

Foster, H. (2001). El retorno de lo real. Madrid: Akal.

Foucault, M. (2014). Las palabras y las cosas. Buenos Aires: Siglo XXI.

Gadamer, H. G. (1998). Verdad y método. Salamanca. Sígueme.

Giunta, A. (2014). ¿Cuándo empieza el arte contemporáneo?, Buenos Aires: Fundación ArteBA.

Goyez Narváez, J. (2015). “Audiovisualidad y subjetividad” en Cuaderno no 56, Poéticas y pedagogías de la imagen, Universidad de Palermo.

Groys, B. (2014).Volverse público. Buenos Aires: Caja Negra Editora.

Groys, B. (2016). Arte en flujo. Buenos Aires. Caja Negra Editora.

Guattari, F. (1996). Caosmosis. Buenos Aires: Manantial.

Kristeva, J. (1980). “Sobre la abyección” en Poderes del horror. Buenos Aires: Siglo XXI.

Kristeva, J. (1999). El lenguaje ese desconocido, Introducción a la lingüística. Madrid: Editorial Fundamentos.

Kristeva, J. (1981). "El gesto, ¿práctica o comunicación? en Semiótica 1, Espiral Ensayos, Editorial Fundamentos.

Kusch, R. “Anotaciones para una Estética de lo Americano" en Comentario No 9, Buenos Aires, diciembre 1955.

Grüner, E. (2001). El sitio de la mirada. Buenos Aires: Grupo Editorial Norma.

Grüner, E. (2003). El fin de las pequeñas historias. Buenos Aires: Paidós.

Marin, L. (1978). Estudios semiológicos (La lectura de la imagen). Madrid: Comunicación.

Niedermaier, A. "La estética 'a la vez' como elemento de lectura de la fotografía contemporánea latinoamericana" en Erbetta Alejandro (comp. 2017) La fotograficidad. Sobre la estética de la fotografía de François Soulages, Arte x Arte. 
Niedermaier, A. La experiencia fotográfica en dialogo con las experiencias del mundo, Cuaderno no 59 (2016), Universidad de Palermo.

Niedermaier, A. “Cuando me asalta el miedo" en Cuaderno no 56 (2015), Poéticas y pedagogías de la imagen, Universidad de Palermo.

Niedermaier, A. (2008). La mujer y la fotografía, una imagen espejada de autoconstrucción y construcción de la historia. Buenos Aires: Leviatán.

Rancière, J. (2010). El espectador emancipado. Buenos Aires: Manantial.

Rancière, J. (2011). El destino de las imágenes. Buenos Aires: Prometeo.

Ricoeur, P. (1984). Educación y política. Buenos Aires: Editorial Docencia.

Sánchez Vázquez, A. "De la estética de la recepción a la estética de la participación” en Marchan Fiz Simón (comp. 2006), Real virtual: redefiniciones ante las nuevas configuraciones espaciales y sociales. Barcelona: Paidós.

Soulages, F. (2016). "Artistas de fronteras, memorias, archivos y artes. Modiano \& Koest" en Fronteras, memorias, Artes y Archivos. Buenos Aires: Arte x Arte.

Soulages, F. (2005). Estética de la fotografía. Buenos Aires: La Marca.

Souto, M. (2016). Pliegues de la formación. Rosario: Homo Sapiens.

Todorov, T. "Enunciación” en Ducrot Oswald, Todorov Tzvetan (2003). Diccionario enciclopédico de las ciencias del lenguaje. Buenos Aires: Siglo veintiuno editores.

Vattimo, G. (1990). La sociedad transparente. Barcelona: Paidós.

Wunenburger, J. (2005). La vida de las imágenes. Buenos Aires: UNSAM.

\begin{abstract}
The contemporaneity and its growing visual turn request a profound research on their various aspects. The image is conceived as a condition of possibility of a certain pensativity (within the distribution of the sensible and the intelligible) and to the different aspects that bring out, small stories, communities, identities, geopolitical aspects and others. It will be also given account of the various manifestations of the visuality, through its symbolic impact and ability to create imaginary, its manifestation as symptom of various problems, the gesture of the producer and finally, its ability for the generation of short stories. The present problems of use will be also analysed and to finish the article some considerations on didactics will be carried out.
\end{abstract}

Keywords: visuality - think capacity - sensitive - comprehensible - teaching.

Resumo: Se o caderno manifesta, em sua totalidade, uma continuidade com o anterior, também realizado entre as Universidades de Palermo e Nacional de Colômbia, este artigo tenta ser uma expansão do que foi expresso no ensaio "Quando o medo me assalta, Eu crio uma imagem" lá abrigada. A contemporaneidade e sua crescente virada visual pedem para aprofundar seus diferentes aspectos. A imagem é concebida como condição da possibilidade de concessão de um pensamento (como uma distribuição do sensível e do inteligível) aos diferentes aspectos que revela, seja cotidiano, pequenas histórias, comunidades, identidades, aspectos geopolíticos e outros. Portanto, esta redação está dividido em duas seções: "Derroteros", no qual você notará as diferentes manifestações da visualidade, através de seu 
impacto simbólico e capacidade de criar imaginário, sua manifestação como sintoma de diferentes problemas, a ação do gesto do produtor e, finalmente, sua aptidão para a geração de histórias. Na seção "A imagem como área de trabalho" será analisada a problemática atual de uso para concluir algumas considerações sobre a narrativa didática necessária a partir dos exames realizados.

Palavras chave: Visualidade - pensativa - sensível - inteligível - didática.

[Las traducciones de los abstracts fueron supervisadas por el autor de cada artículo] 